\title{
EFFICACY OF PENICILLIUM CHRYSOGENUM STRAIN SNEF1216 AGAINST ROOT-KNOT NEMATODES (MELOIDOGYNE INCOGNITA) IN CUCUMBER (CUCUMIS SATIVUS L.) UNDER GREENHOUSE CONDITIONS
}

\author{
SIKANDAR, A. ${ }^{1}$ - ZHANG, M. Y. ${ }^{1}-$ ZHU, X. F. ${ }^{1}-$ WANG, Y. Y. ${ }^{2}-$ AHMED, M. ${ }^{3}$ - IQBAL, M. F. ${ }^{2}-$ \\ JAVEED, A. ${ }^{2}$ - XUAN, Y. H. ${ }^{1}-$ FAN, H. Y. ${ }^{1}-$ LIU, X. Y. ${ }^{4}-$ CHEN, L. J. ${ }^{1}-$ DUAN, Y. X. ${ }^{1 *}$ \\ ${ }^{I}$ Nematology Institute of Northern China, Shenyang Agricultural University \\ 120 Dongling road, Shenyang 110866, China \\ ${ }^{2}$ College of Biosciences and Biotechnology, Shenyang Agricultural University \\ 120 Dongling road, Shenyang 110866, China \\ ${ }^{3}$ College of Plant Protection, Shenyang Agricultural University \\ 120 Dongling road, Shenyang 110866, China \\ ${ }^{4}$ College of Sciences, Shenyang Agricultural University \\ 120 Dongling road, Shenyang 110866, China \\ *Corresponding author \\ e-mail: duanyx6407@163.com; phone: +86-13-99825-3910
}

(Received $12^{\text {th }}$ May 2019; accepted $16^{\text {th }}$ Jul 2019)

\begin{abstract}
Root-knot nematode (Meloidogyne incognita) has become a serious risk for cucumber globally. Haphazard use of synthetic chemicals poses a serious threat to agricultural crops, eliminating predators and also polluting natural community. Thus these negative effects led towards development of ecofriendly approaches which are safe and effective for $M$. incognita management. The study has been planned to coat seeds with Snef1216 (Penicillium chrysogenum) and evaluate its ability to control $M$. incognita in cucumber. It reduced $M$. incognita invasion rate significantly in different inoculums $500 \mathrm{~J} 2$ (second stage juveniles) $67.09 \%$ followed by $1000 \mathrm{~J} 2$ and $2000 \mathrm{~J} 2$ plant $^{-1} 60.44 \%$ and $36.02 \%$, respectively. It inhibited development of nematodes $60.30 \%, 50.37 \%$ and $38.77 \%$ at 500,1000 and $2000 \mathrm{~J}_{2}$ plant $^{-1}$ inoculation levels respectively compared to control. Snef1216 reduced significant $(\mathrm{P}<0.05)$ reproduction rate at 500J2 (69.46\%), 1000J2 (62.89\%) and 2000J2 (63.62\%) of M. incognita. It interfered in galls formation and nematodes $\mathrm{g}^{-1}$ in root mass. Snef1216 enhanced seed germination (22.09\%) with germination index $(53.77 \%)$ and germination rate $(64.49 \%)$. Additionally, seed dressing with Snef 1216 exhibited additional biomass, reduced invasion of second-stage juveniles and also restrained development of nematode. Our results suggest that Snef1216 can be introduced as a biomass enhancer and potential bio-control agent against $M$. incognita in cucumber.
\end{abstract}

Keywords: biological control, seed dressing, invasion, penetration, biological control agents, biomass

\section{Introduction}

Plant parasitic nematodes can easily damage crops not only by direct feeding but also acting as a facilitator for other organisms (Palomares-Rius et al., 2017; Smant et al., 2018). However, damage caused by nematodes is often not easy to differentiate from other agents due to their microscopic size. These are usually soil, roots and leaves inhibiting microorganisms cause an enormous threat to agriculture, manifested in up to 157 billion US\$ worth of damage (Youssef et al., 2013).

Root-knot nematodes (RKNs) are common and have an extremely broad host range which includes more than 5500 plant species (Trudgill and Blok, 2001). Among 
different genera, Meloidogyne is one of the most destructive plant parasitic nematodes (Xiang et al., 2017; Li and Chen, 2017). However, four main species of this genus, i.e. Meloidogyne incognita, Meloidogyne hapla, Meloidogyne arenaria and Meloidogyne javanica have been reported to decrease yields, among them $M$. incognita is one of the most widespread species (Dong et al., 2014).

Cucumber (Cucumis sativus) is a commonly cultivated plant belonging to the family Cucurbitaceae, is ranked as an important vegetable globally (Sebastian et al., 2010; Mao et al., 2016). However, China has been ranked as number one and accepted as the world's largest producer of cucumber (FAOSTAT, 2018). This is an important vegetable crop cultivated widely throughout the country, especially in North China (Tian et al., 2011; Huang et al., 2014; Huang et al., 2016). The researcher reported that about 50\% of vegetables grown in greenhouse infected by root-knot nematodes with annual loss up to 400 million US dollars (Huang et al., 2014) and it is hard for farmer to diagnose its damage due to similarities with nutritional deficiencies such as chlorosis (Zeng et al., 2018).

The infestation of $M$. incognita adversely affects the growth of the plant, yellowing and stunted leaves growth and ultimately the destruction of whole plants due to absorption of important nutrients (Escobar et al., 2015; Li and Chen, 2017). Infected roots showed bushier and shorter length compared with healthy roots (Miyashita et al., 2014). They directly feed upon plants and caused the lesion in it which helps in development of secondary pathogens such as pathogenic bacteria, fungus and viruses which caused secondary infections (Smant et al., 2018). Unfortunately, it is difficult to control it in soil because of its interaction with other pathogens and plant-parasitic nematodes (PPNs), and developing disease complextion (Back et al., 2002; Divon and Fluhr, 2007; Son et al., 2009; Björsell et al., 2017).

Chemical nematicides have been used to control this pest but their continues and indiscriminate use poses adverse effects on soil and environment (Huang et al., 2014). Due to their hazardous effect on human, availability of such pesticides has become limited in local markets such as methyl bromide, ethylene dibromide (EDB) and dibromochloropropane (Oka et al., 2000; Gotlieb et al., 2003; Dong and Zhang, 2006; Nicol et al., 2011; Onkendi et al., 2014). To overcome this problem, eco-friendly and safe approaches for prevention and management of this nematode are needed urgently because root-knot nematodes have high reproduction rates and short generation times (Trudgill and Blok, 2001; Jang et al., 2016). With increasing demands of organic and chemical free crops, there is a dire need to develop strategies for this destructive pathogen (Huang et al., 2014; Kokalis-Burelle, 2015).

Signs of Progress in recent decades regarding biocontrol agents have led to several products. Biological control is usually safe as compared to chemical control. Meanwhile, Fungi belonging to genera Fusarium, Trichoderma, Phyllosticta, Acremonium, Chaetomium, Paecilomyces, and Penicillium have been known as antagonistic to plant-parasitic nematodes (Kalele et al., 2007; Govinden-Soulange and Levantard, 2008; Sharon et al., 2009; Siddiqui and Akhtar, 2009). Within an integrated and more sustainable management strategy the use of biocontrol agents, like P. chrysogenum, seems to be a promising alternative in the future. However, some studies reported the effectiveness of such fungus against $M$. incognita in different crops. The biocontrol effect against different pathogens in the presence of $P$. chrysogenum is reported in a wide range of plants and pathogens providing evidence for the effect of P. chrysogenum on nematode infection. Dry mycelium enhanced plant growth and 
reduced root galls to protect cucumber and tomato plants against $M$. javanica (Gotlieb et al., 2003). P. chrysogenum used alone and in the combination of two (Aspergillus niger, Plant growth promoting rhizobacteria PGPRS and Arbuscular mycorrhizal fungi) could boost plant growth and reduce reproduction of $M$. incognita in tomato (Siddiqui and Akhtar, 2009). Yao et al. (2014) also reported that $P$. chrysogenum is one of the most important fungi to control $M$. incognita in tomato. Thus, keeping in view the biocontrol potential of Snef1216 (P. chrysogenum) against $M$. incognita on different crops, the present study was planned to explore the nematicidal activity of fungus fermentation for control of $M$. incognita by seeds dressing on cucumber seeds and to enhance biomass at Nematology Institute of Northern China, Shenyang Agricultural University, Liaoning, China. The results of the present study should help as a theoretical foundation for the development of marketable and valuable biocontrol agent.

\section{Material and methods}

\section{Experimental design}

The study has been designed to evaluate the efficacy of Snef1216 (Penicillium chrysogenum) against $M$. incognita on cucumber by seed coating with randomized complete block design (RCBD) during 2018. Each treatment have been replicated five time.

\section{Preparation of PDA}

$200 \mathrm{~g}$ of potatoes were boiled in $1 \mathrm{~L}$ of distilled water and filtered through cheesecloth on becoming soft. After that, $20 \mathrm{~g}$ of glucose and $17 \mathrm{~g}$ of agar were added into it and boiled again for 1 minute. Then, $100 \mathrm{ml}$ PDA was poured in $250 \mathrm{ml}$ conical flasks and sealed. PDA containing flask were sterilized into a steam autoclave machine for 30 minutes at $121^{\circ} \mathrm{C}$ and preserved at room temperature.

\section{Activation of Strain Snef1216 (Penicillium chrysogenum)}

P. chrysogenum strain Snef1216 was obtained from the China General Microbiological Culture Collection Center. Jiang et al. (2011) identified it and stored at $-80^{\circ} \mathrm{C}$ at Nematology Institute of Northern China (NINC), Shenyang Agricultural University, China. Before use, a small quantity of strain was added into PDA filled cavities by the help of a sterilized needle and placed into an incubator for 7 days at $25-28^{\circ} \mathrm{C}$ for the confirmation and purity level and strain activation.

\section{Fermentation preparation}

For the preparation of fermentation (nutrition medium) $50 \mathrm{~g}$ Sucrose, $8 \mathrm{~g} \mathrm{NaNO}_{3}, 2 \mathrm{~g}$ $\mathrm{K}_{2} \mathrm{HPO}_{4}, 0.08 \mathrm{~g} \mathrm{MgSO}_{4} .7 \mathrm{H}_{2} \mathrm{O}, 0.4 \mathrm{~g} \mathrm{KCl}$, and $0.003 \mathrm{~g} \mathrm{FeSO}_{4} .7 \mathrm{H}_{2} \mathrm{O}$ were mixed together into $1000 \mathrm{ml}$ distill water and the consequent mixture was boiled for few minutes. Then, $100 \mathrm{ml}$ nutrition medium was poured into $250 \mathrm{ml}$ conical flasks and sterilized into steam autoclave machine for 30 minutes at $121^{\circ} \mathrm{C}$. Five fungus cakes were added ( $1 \mathrm{~mm}$ diameter of each) into $100 \mathrm{ml}$ nutrition medium and put on a shaker for 3 days at $28^{\circ} \mathrm{C}$ and $150 \mathrm{rpm}$. After that, $100 \mathrm{ml}$ new medium was poured into each flask and were again put on a shaker for 8 days at $28^{\circ} \mathrm{C}$ and $150 \mathrm{rpm}$ for fermentation development and then stored at $4^{\circ} \mathrm{C}$ after filtration (Jiang et al., 2011). 


\section{Sterilization of seeds and seeds coating}

Seeds were surface sterilized by $1-2 \mathrm{ml} 75 \%$ ethanol and $0.05 \%$ Tween 20 . After that 1-2 $\mathrm{ml} \mathrm{95 \%} \mathrm{ethanol} \mathrm{was} \mathrm{added} \mathrm{and} \mathrm{left} \mathrm{for} 1$ minute then, 1-2 $\mathrm{ml}$ absolute ethanol was added and allowed for a few minutes to rinse with sterilized distilled water and airdried. After that seeds were divided equally into two Petri dishes, half-seeds were coated with Snef1216 ( $P$. chrysogenum) and half were taken as a control treatment. Uncoated or control seeds were placed into Petri dish containing double layers of wet filter papers for seed germination. For seeds coating, fermentation of Snef1216 ( $P$. chrysogenum) was added and properly mixed for uniform coating on all seeds and left for complete drying, and was placed into Petri dish containing double layers of wet filter papers for seed germination. Germination \% (G\%), germination index (GI), and germination rate (GR) were calculated by Eqs.1-3 (Bartlett, 1937; Mukhtar, 2008; Mukhtar et al., 2012).

$$
G \%=\frac{N \cdot G . S}{T \cdot N . S} \times 100
$$

Whereas, N.G.S. is no. of germinated and T.N.S. is total no. of seeds.

$$
G I=\frac{N \cdot G \cdot S \cdot(1)}{D \cdot C \cdot(1)}+\frac{N \cdot G \cdot S \cdot(2)}{D \cdot C \cdot(2)}+\frac{N \cdot G \cdot S \cdot(f)}{D \cdot C \cdot(f)}
$$

Whereas, N.G.S. (1), N.G.S. (2) and N.G.S. (f) are the numbers of germinated seeds in $1^{\text {st }}, 2^{\text {nd }}$ and final counts; D.C. (1), D.C. (2) and D.C. (f) are stand for days to $1^{\text {st }}, 2^{\text {nd }}$ and final counts.

$$
G R=\frac{a+(a+b)+(a+b+c)(a+b+c+m)}{n(a+b+c+m)}
$$

Whereas, $\mathrm{a}, \mathrm{b}$ and $\mathrm{c}$ are the number of seedling in the first, second and third counts, $\mathrm{m}$ stands for the number of seedling in final count and $\mathrm{n}$ is number of counts.

Germinated seedlings were transferred into seedling trays which were filled with sterilized substrate. At four leaves stage plants were transferred into pots $(20 \mathrm{~cm}$ diameter), those filled with 800-1000 g sterilized sand, soil and substrate (1:1:1).

\section{Nematode Inoculums}

The population of root-knot nematode (M. incognita) was maintained in tobacco and tomato plants, grown in greenhouse of Nematology Institute of Northern China (NINC), Shenyang Agricultural University, China. Plants were uprooted and roots were washed gently then, cut into 1-2 cm pieces and macerated for 30 seconds in a small amount of water by using the electric blender. Macerate was transferred into the funnel and added $0.05 \% \mathrm{NaOCl}$ into it. The mixture was manually shaken for 1-2 minutes to separate the eggs from the gelatinous matrix. Then, the suspension was poured through 200 and $500 \mu \mathrm{m}$ size meshes respectively and washed with tap water to remove $\mathrm{NaOCl}$. Eggs were further purified by centrifugation in $454 \mathrm{~g} \mathrm{~L}^{-1}$ sucrose for 4 minutes at $3000 \mathrm{rpm}$. The supernatant was poured into $25 \mu \mathrm{m}(500 \mu \mathrm{m}$ mesh and rinsed several times with 
sterilized water. Eggs inoculums were transferred into a funnel and allowed to hatch into second stage juveniles (J2). These (J2) were then allowed to crawl through eight layers of Kim-wipe tissues into sterilized water by using the Baermann funnels method (Baermann, 1917). The J2 in the resulting suspension adjusted at 500J2, 1000J2 and $2000 \mathrm{~J} 2 / 3 \mathrm{ml}$ used as inoculums. These inoculums were injected $2-4 \mathrm{~cm}$ deep into rhizosphere with a plastic rod into 3 holes made around the base of the stem (Selim, 2010). The plants were monitored regularly to examine the different stages of the nematodes in the roots at different intervals viz., 7, 14, 21 and 28 dpi (days post inoculation).

\section{Staining of roots}

Plants were uprooted; carefully washed the roots under running tap water to remove soil particles and bleached in 10, 20 and $30 \mathrm{ml}$ for young, mature and older roots respectively. Bleaching process was performed in $5.25 \% \mathrm{NaOCl}$ into $50 \mathrm{ml}$ distilled water for 4 minutes and washed for 45 seconds under running water and soaked into distilled water for 15 minutes. For stain preparation, $1 \mathrm{ml}$ fuchsin acid was added into $30-50 \mathrm{ml}$ distilled water and heated for 1 minute in the microwave. Then these roots were put into the preheated stain and reheated the stain untill boils. Washing was performed under water for color fading. Then, 2-3 drops of $5 \mathrm{~mol} / \mathrm{L} \mathrm{HCl}$ was added into 20-30 ml glycerol heated and placed the roots into it. Roots were examined after cooling under the microscope and observed different stages of RKN (Hussey, 1985).

\section{Growth Index observation and determination}

Growth parameters like plant height $(\mathrm{cm})$ by using scale, stem diameter $(\mathrm{mm})$ by using Vernier calipers, root length $(\mathrm{cm})$, root and shoot weight $(\mathrm{g})$ were calculated. Leaf area (LA) was calculated by using Eq.4 Quarrie and Jones equation (Aldesuquy et al., 2014; Ahmad et al., 2015). Germinated plants were maintained in greenhouse at ambient light at $26-32^{\circ} \mathrm{C}$ and were irrigated by showering of tap water with the interval of three days. Five plants were selected randomly from each treatment at 28 dpi (Days post inoculation) for evaluating the variation among growth parameters.

$$
L A=(\text { Length } \times \text { Width }) \times 0.75
$$

Following treatments were used (T1) control with (2000 J2) RKN (T2); control with (1000 J2) RKN; (T3) control with (500 J2) RKN; (T4) control without inoculation (T5); Coated or treated with (2000 J2) RKN; (T6) Coated or treated with (1000 J2) RKN; (T7) Coated or treated with (500 J2) RKN; (T8) coated or treated without inoculation.

\section{Statistical Analysis}

In order to assess the significant effects of all treatments on cucumber, all recorded data were analyzed by one-way Analysis of Variance (ANOVA). Mean difference between treatments were calculated for the significance test through Duncan's multiple range test $(P>0.05)$. All statistical processes were administered by different statistical packages such as IBM-SPSS statistics 25.0 version software and MS Excel. Graphs were constructed through Sigma Plot 10.0 software. 


\section{Results}

\section{Seed Germination}

The effect of fermentation on the seed germination is shown in Fig. 1A, B and $C$. Significant difference among treatments was observed. However, significant results $(\mathrm{P}<0.05)$ showed that seeds coated with fermentation broth of Snef1216 (P. chrysogenum) were found efficient to enhance $22.09 \%$ germination $(\mathrm{G} \%)$ compared to control. Seed germination index (GI) noticeably demonstrated the potential of Snef1216 ( $P$. chrysogenum) which increased to $53.77 \%$. While, germination rate was boosted to $64.49 \%$ by pretreated seeds with fermentation as compared to control.
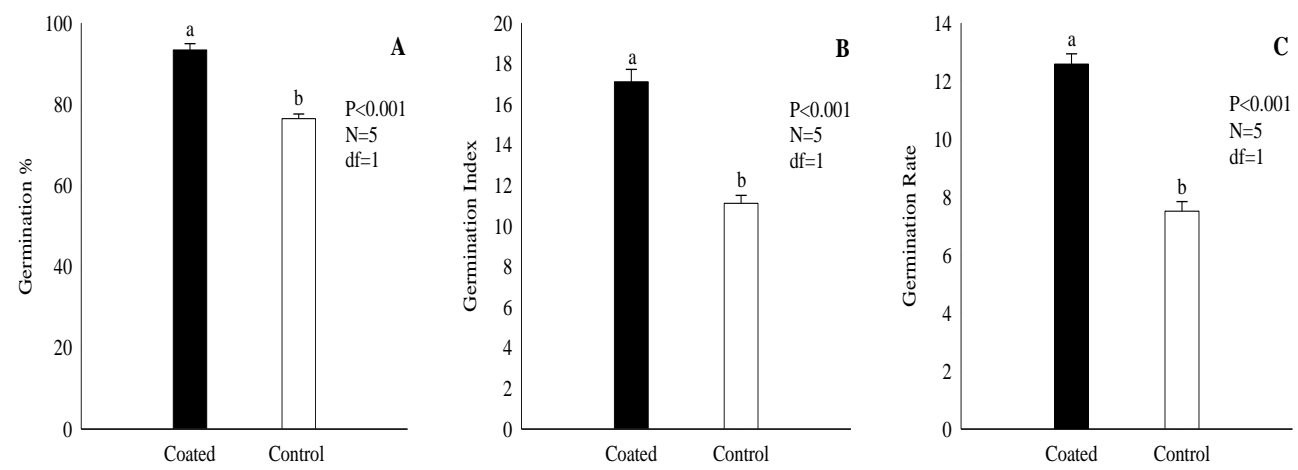

Figure 1. (A) Germination percentage of cucumber seeds. (B) Germination index of treated and untreated seeds. (C) Effect of coating on germination rate. The error bars illustrated the mean \pm Standard error. Different letters on bar indicates that values are significantly different according to Duncan's multiple range test at $P>0.05$

\section{Growth Parameters}

Table 1 and Fig. 2 demonstrated that all treated seed efficiently promoted plant growth; like maximum plant height, $104.3 \mathrm{~cm}$ was observed in T8 followed by T4 and T7 96.8 and $94.9 \mathrm{~cm}$, respectively.

Table 1. Treatment effect on growth parameters of cucumber plants infected Meloidogyne incognita

\begin{tabular}{|c|c|c|c|c|c|c|}
\hline \multirow[b]{2}{*}{ Treatments } & \multicolumn{6}{|c|}{ Growth Parameters } \\
\hline & $\begin{array}{c}\begin{array}{c}\text { Plant height } \\
\text { (cm) }\end{array} \\
\end{array}$ & $\begin{array}{c}\text { Stem diameter } \\
(\mathrm{mm})\end{array}$ & $\begin{array}{c}\text { Leaf area } \\
\left(\mathrm{cm}^{2}\right)\end{array}$ & $\begin{array}{l}\text { Root length } \\
\text { (cm) }\end{array}$ & $\begin{array}{c}\text { Shoot weight } \\
\text { (g) }\end{array}$ & $\begin{array}{c}\text { Root weight } \\
\text { (g) }\end{array}$ \\
\hline $\mathrm{Ck}+2000 \mathrm{~J}_{2}(\mathrm{~T} 1)$ & $66.7 \pm 2.8^{\mathrm{e}}$ & $4.7 \pm .01^{\mathrm{f}}$ & $72.5 \pm 2^{\mathrm{h}}$ & $20.3 \pm 0.9^{g}$ & $27.8 \pm 2.1^{\mathrm{f}}$ & $6.3 \pm .2^{\mathrm{e}}$ \\
\hline $\mathrm{Ck}+1000 \mathrm{~J}_{2}(\mathrm{~T} 2)$ & $70.2 \pm 1.7^{\mathrm{d}}$ & $5.1 \pm .03^{\mathrm{e}}$ & $77.2 \pm 1^{\mathrm{g}}$ & $23.8 \pm 1.4^{\mathrm{f}}$ & $29.1 \pm 2.4^{\mathrm{ef}}$ & $6.9 \pm .1^{\mathrm{e}}$ \\
\hline $\mathrm{Ck}+500 \mathrm{~J}_{2}(\mathrm{~T} 3)$ & $75.5 \pm 1.5^{\mathrm{c}}$ & $5.1 \pm .04^{\mathrm{e}}$ & $80.4 \pm 1^{\mathrm{f}}$ & $24.4 \pm 1.5^{\mathrm{f}}$ & $30.9 \pm 1.1^{\mathrm{e}}$ & $7.9 \pm .2^{\mathrm{d}}$ \\
\hline $\mathrm{Ck}$ no $\mathrm{J}_{2}(\mathrm{~T} 4)$ & $76.7 \pm 2.8^{\mathrm{c}}$ & $5.3 \pm .05^{\mathrm{d}}$ & $86.7 \pm .3^{\mathrm{e}}$ & $28.8 \pm 0.8^{\mathrm{e}}$ & $36.4 \pm 1.5^{\mathrm{d}}$ & $9.6 \pm .1^{\mathrm{c}}$ \\
\hline Trt. $+2000 \mathrm{~J}_{2}(\mathrm{~T} 5)$ & $93.7 \pm 2.8^{\mathrm{b}}$ & $6.2 \pm .03^{\mathrm{c}}$ & $103.3 \pm 1^{\mathrm{d}}$ & $31.3 \pm 1.8^{\mathrm{d}}$ & $40.8 \pm 2.3^{c}$ & $9.4 \pm .1^{\mathrm{c}}$ \\
\hline Trt. $+1000 \mathrm{~J}_{2}(\mathrm{~T} 6)$ & $94.9 \pm 2.5^{\mathrm{b}}$ & $6.2 \pm .02^{\mathrm{bc}}$ & $106.4 \pm 0^{c}$ & $35.4 \pm 1.4^{\mathrm{c}}$ & $45.1 \pm 2.1^{\mathrm{b}}$ & $9.9 \pm .1^{\mathrm{c}}$ \\
\hline Trt. $+500 \mathrm{~J}_{2}(\mathrm{~T} 7)$ & $96.8 \pm 2.8^{\mathrm{b}}$ & $6.4 \pm .01^{\mathrm{b}}$ & $109.5 \pm 1^{b}$ & $39.2 \pm 1.0^{\mathrm{b}}$ & $47.7 \pm 2.2^{\mathrm{b}}$ & $11.9 \pm 0^{\mathrm{b}}$ \\
\hline Trt. no $\mathrm{J}_{2}(\mathrm{~T} 8)$ & $104.3 \pm 3^{\mathrm{a}}$ & $6.6 \pm .03^{\mathrm{a}}$ & $116.2 \pm 2^{\mathrm{a}}$ & $45.3 \pm 2.4^{\mathrm{a}}$ & $52.1 \pm 2.2^{\mathrm{a}}$ & $16.6 \pm 2^{\mathrm{a}}$ \\
\hline \multicolumn{7}{|c|}{ ANOVA Test } \\
\hline Sum of square & 699.459 & 18.182 & 9755.19 & 2526.216 & 2867.608 & 381.197 \\
\hline Mean Square & 998.780 & 2.597 & 1393.60 & 360.888 & 409.658 & 54.457 \\
\hline F-value & 156.631 & 101.247 & 1008.11 & 166.394 & 103.964 & 182.451 \\
\hline
\end{tabular}

Data repesent the Mean \pm Standard deviation of growth parameters. The different letter within columns are significantly different according to Duncan's multiple range test $(\mathrm{P}>0.05)$ 
Significant $(\mathrm{P}<0.05)$ stem diameter was recorded in $\mathrm{T} 86.6 \mathrm{~mm}$ followed by $\mathrm{T} 7$ and T6 6.4 and $6.2 \mathrm{~mm}$, respectively. The leaf area was ranged between $72.5-116.2 \mathrm{~cm}^{2}$ in $\mathrm{T} 1$ and T8. Maximum root length observed was $45.30 \mathrm{~cm}$ in T8 compared to a minimum in T1 $20.3 \mathrm{~cm}$. Similarly, the highest shoot and root weight was recorded in T8 52.1 and $16.6 \mathrm{~g}$ compared to $\mathrm{T} 127.8$ and $6.3 \mathrm{~g}$. The results revealed that pathogenicity of root-knot nematode (RKN) at different levels of inoculums viz., 500, 1000 and $2000 \mathrm{~J} 2$ of $M$. incognita per pot resulted into a significant $(\mathrm{P}<0.05)$ decrease in plant growth, however, treated plants showed significant biomass over control.

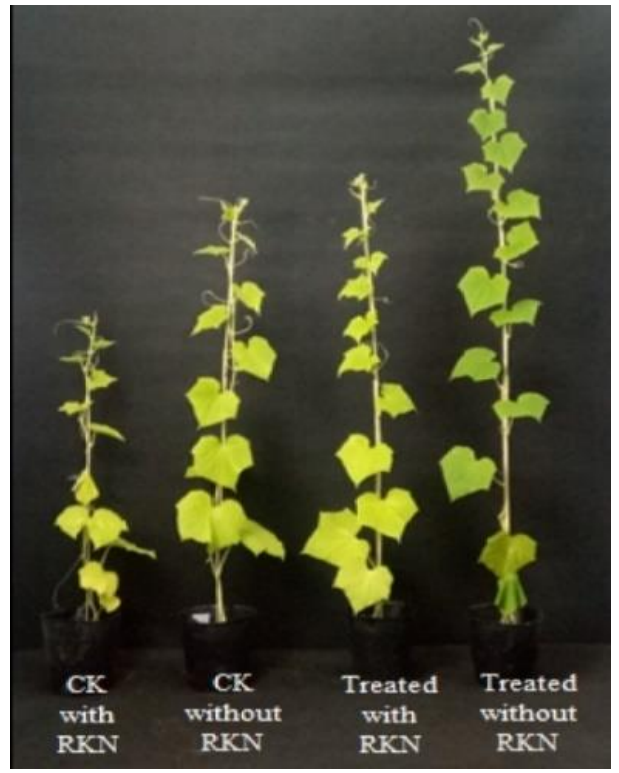

Figure 2. Efficacy of coating of Snef 1216 (P. chrysogenum) on the growth of cucumber

\section{Nematode Infection}

The Snef1216 P. chrysogenum was tested for its potential control toward $M$. incognita on the cucumber plant. The plants were monitored regularly to examine the different stages of the nematodes in roots at different intervals viz., 7, 14, 21 and 28 dpi (days post inoculums). Data presented in Figs. 3 and 4. showed that all the seed treated with Snef1216 efficiently reduced the penetration rate of $\mathrm{J} 2$ into cucumber roots at different inoculums levels such as 500J2/plant reduced invasion $67.09 \%$ followed by 1000 and 2000J2/plant 60.44 and $36.02 \%$, respectively. It also inhibited the development of nematodes (J3 and J4) like 500J2/plant reduced $60.30 \%$ followed by 1000 and 2000J2/plant 50.37 and $38.77 \%$, respectively. Similarly, rate of reproduction was 69.46, 62.89 and $63.62 \%$ at the same inoculation level (Figs. 3 and 4). At 7 dpi and 28 dpi less nematode population were present. Whereas, at all dpi-s control plants had highest population of nematodes while, seed treated with Snef1216 (P. chrysogenum) showed significantly fewer nematodes (Fig. 5). It was also observed that fewer females and males were developed in treated plants resulting in the development of few egg masses compared to control. It is obvious from results that the Snef1216 ( $P$. chrysogenum) exhibited a drastic reduction in galls and no. of nematodes per gram of root weight as compared with control at different inoculum levels viz., 500, 1000 and 2000J2/per plant (Fig. 6). 


\section{Discussion}

Seed dressing with fungus enhanced germination percentage, germination index, and germination rate. However, seed treatment with non-pathogenic inoculants like fungus showed boosted seed germination rate, seedling vigor and reduced the occurrence of pathogenic infections (Zheng and Shetty, 2000; Bharath et al., 2006; Dubey et al., 2007). Seed treated with Trichoderma species enhanced the germination parameters (Oyarbide et al., 2001; Mukhtar, 2008; Asaduzzaman et al., 2010; Mukhtar et al., 2012). Seed treatment with fermentation broth of Snef1216 could be an effective and reasonable way to enhance the germination of cucumber and reduce nematodes invasion in plant roots.

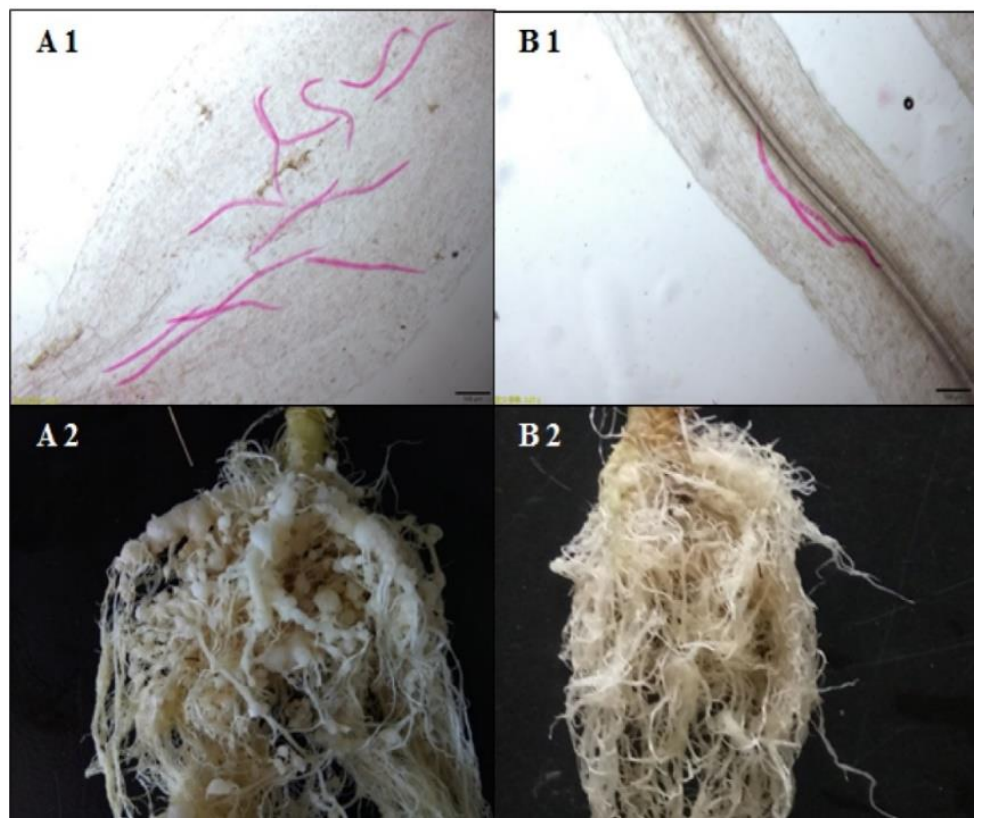

Figure 3. (A1 and A2) Roots of seeds without coating. (B1 and B2) Roots of seeds coated with Snef 1216 ( $P$. chrysogenum) fermentation

The results indicated that seed coating resulted in increased biomass with low nematodes attack at different inoculums levels viz., 500, 1000 and $2000 \mathrm{~J} 2 /$ per pot as compared to their controls. Thus, our results are agree with Duggal et al. (2017) who reported that the pathogenic level of root-knot nematode in different inoculums viz., 0 , $10,100,1000$ and $10000 \mathrm{~J} 2 /$ pot resulted into significant reduction in plant growth parameters like plant height, root and shoot weight at or above $1000 \mathrm{~J} 2$ inoculums level. It was also reported that plant growth was inversely proportional to inoculums levels, at highest inoculums plant showed less biomass or vice versa. Vos et al. (2012) and Banuelos et al. (2014) supported our findings that Arbuscular mycorrhizal fungi improved plant growth and vigor in brinjal, tomato, and ornamental plants. Syncephalastrum racemosum efficiently increased plant growth in cucumber (Huang et al., 2014). Siddiqui and Akhtar (2009) described that antagonistic fungi ( $P$. chrysogenum and A. niger) efficiently enhanced the tomato growth and significantly reduced gall formation. Seed treatment with fungus Snef1216 ( $P$. chrysogenum) efficiently promoted the growth parameters compared to control at different levels of inoculums and play a vital role in the promotion of plant growth. 

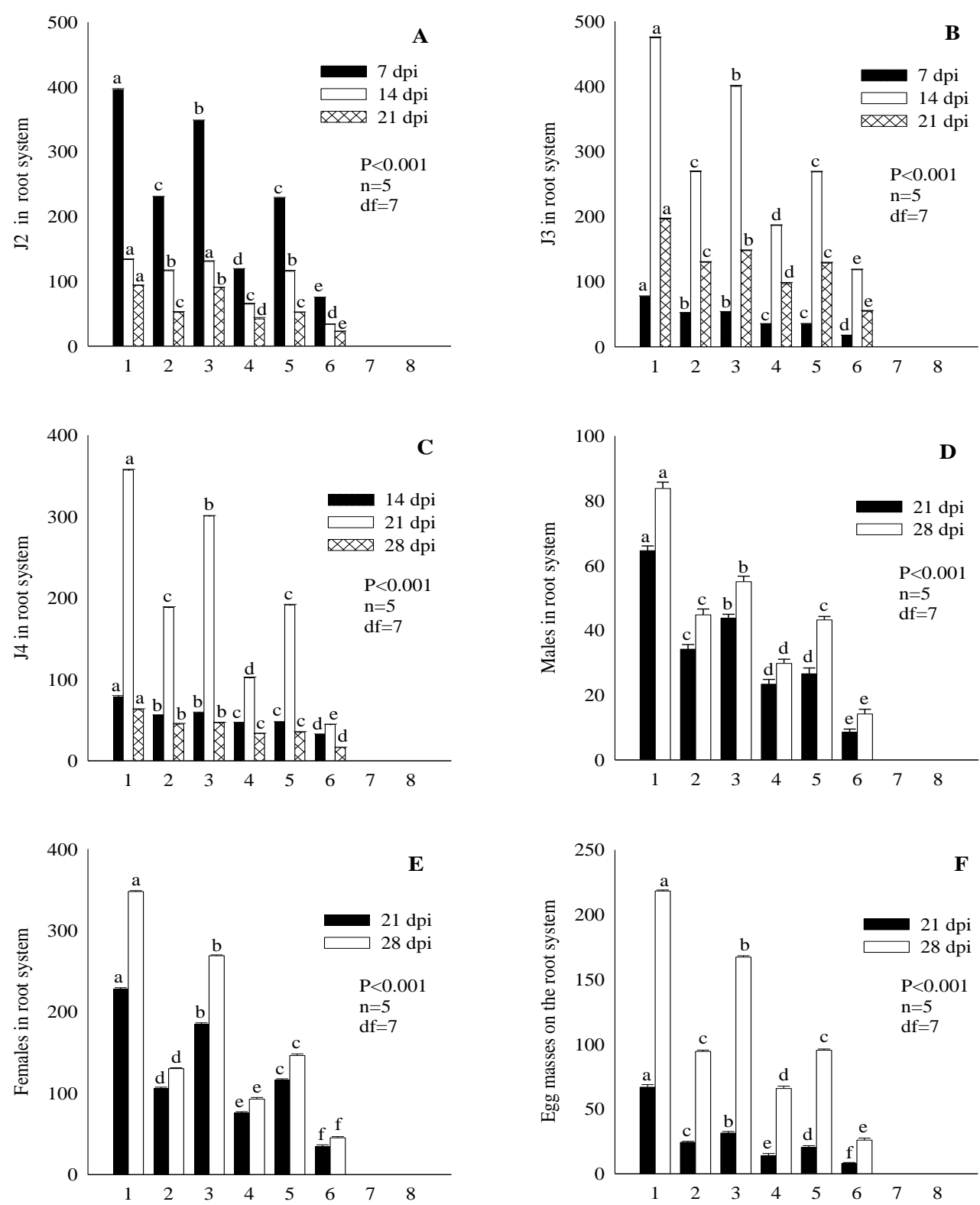

Figure 4. (A) Number of $J 2$ in the root system. (B) Number of J3 in the root system. (C) Number of $\mathrm{J} 4$ in the root system. (D) Number of males in the root system. (E) Number of females in the root system. $(F)$ Number of egg masses on the root. The error bars illustrated the mean \pm standard error. Different letters on bar indicates that values are significantly different according to Duncan's multiple range test at $P>0.05$. $(1=C K+2000 J 2 ; 2=$ Treated $+2000 J 2$;

$3=C K+1000 \mathrm{~J} 2 ; 4=$ Treated $+1000 \mathrm{~J} 2 ; 5=C K+500 \mathrm{~J} 2 ; 6=$ Treated $+500 \mathrm{~J} 2 ; 7=C K$-without inoculation, $8=$ Treated-without inoculation)

Seed treated with endophytic fungi like Fusarium, Trichoderma, Chaetomium, Acremonium, Paecilomyces, and Phyllosticta potentially control $M$. incognita in cucumber (Siddiqui and Akhtar, 2009; Yan et al., 2011). Seed treatment used as a standard way for the application of $P$. chrysogenum that could concurrently confer resistance to root-knot nematodes in agricultural. Mascarin and Junior (2012) reported 
that $T$. harzianum efficiently decrease the population of $M$. incognita in cucumber and enhanced plant growth under greenhouse conditions. A. niger had the ability to inhibit the $M$. incognita in tomato (Jang et al., 2016). Fusarium oxysporum showed repelling effect towards $M$. incognita in tomato as well as promoted plant growth (Selim, 2010; Terra et al., 2018). Gotlieb et al. (2003) reported that dry mycelium enhanced plant growth and reduced root galls to protect cucumber and tomato against $M$. javanica. Our findings clearly demonstrated that seed treatment with fungus Snef1216 ( $P$. chrysogenum) significantly reduced the infection of root-knot nematode and lowered the number of $2^{\text {nd }}$ stage juvenile's invasion in to cucumber roots. The pathogenic level of $M$. incognita in capsicum under greenhouse condition was observed that number of galls, egg masses was increased with increase in levels of inoculum conspicuously at and above $1000 \mathrm{~J} 2$ level (Duggal et al., 2017). Our results also revealed that pathogenic level of root-knot nematode was also observed in cucumber that the number of galls and egg masses was increased with increase in inoculums level while, seeds treated with Snef1216 significantly reduced compared to control. It also inhibited the development and rate of reproduction of nematodes in the roots. Cucumber is susceptible and an excellent host for multiplication of $M$. incognita but, seeds treated with Snef1216 significantly reduced the infection of nematodes and galls at a different level of inoculums also enhanced biomass.

Although different biological control approaches have been employed in current agriculture system to control nematodes on crops and vegetables, but seed dressing with strain Snef1216 on cucumber is limited. The outcomes from this study presented that Snef1216 is useful as a seed dressing, in order to decrease nematode infection. These results showed that seed dressing could be an effective alternative and reasonable way to control M. incognita.

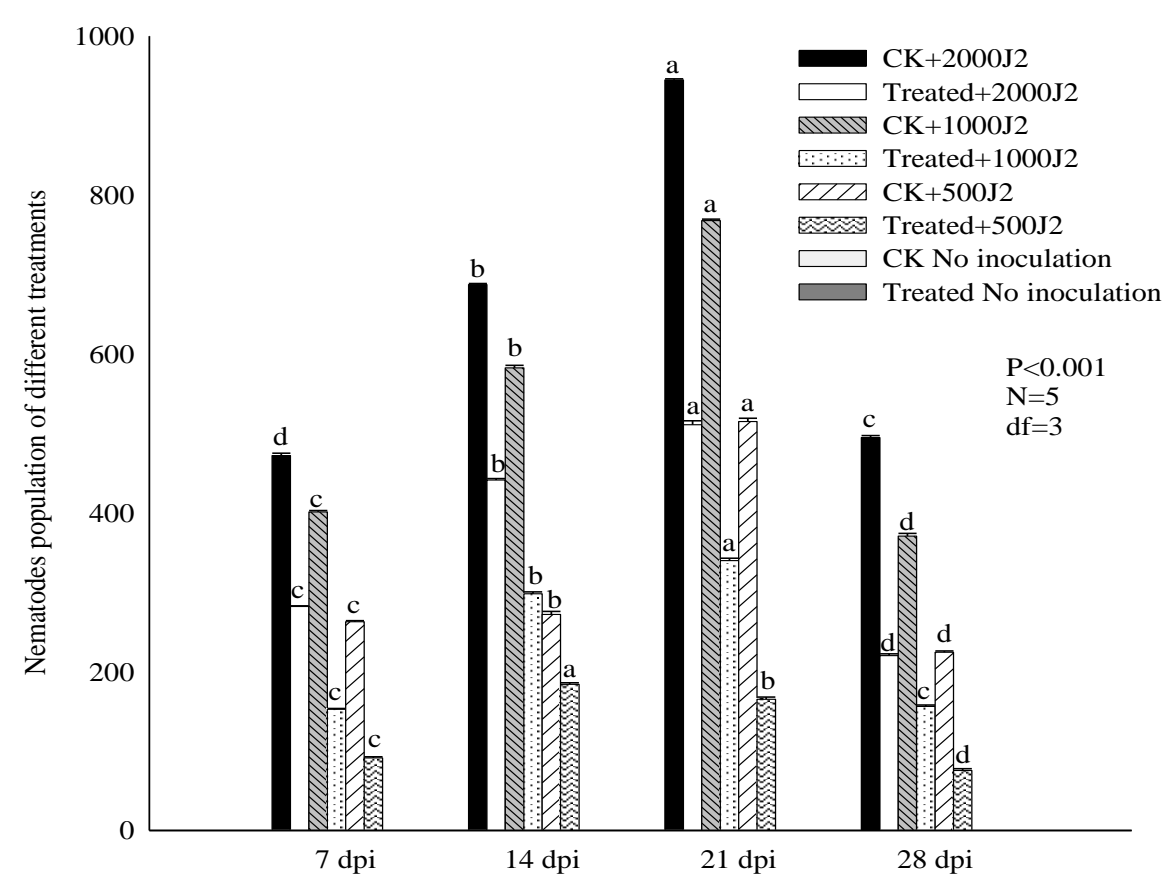

Figure 5. Population of nematodes in different treatments at different dpi. The error bars illustrated the mean \pm standard error. Different letters on bar indicates that values are significantly different according to Duncan's multiple range test at $P>0.05$ 

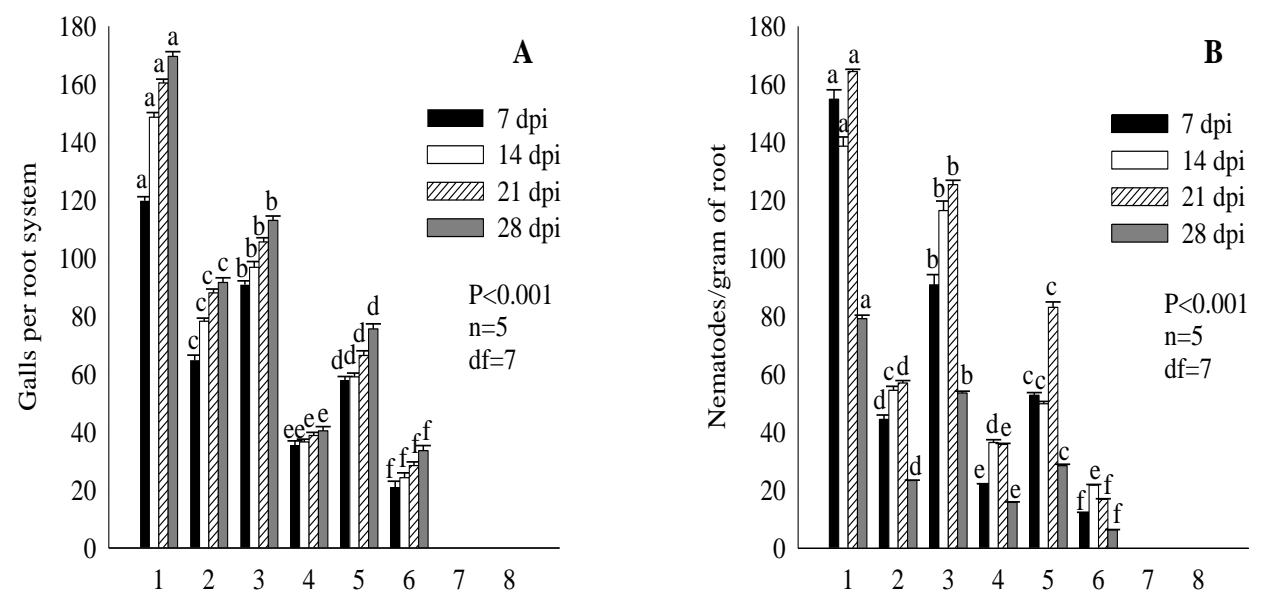

Figure 6. (A) Number of galls per root system. (B) Number of nematodes present in per gram of root. The error bars illustrated the mean \pm standard error. Different letters on bar indicates that values are significantly different according to Duncan's multiple range test at $P>0.05$. $(1=$ $C K+2000 \mathrm{~J} 2 ; 2=$ Treated $+2000 \mathrm{~J} 2 ; 3=C K+1000 \mathrm{~J} 2 ; 4=$ Treated $+1000 \mathrm{~J} 2 ; 5=C K+500 \mathrm{~J} 2$; $6=$ Treated $+500 \mathrm{~J} 2 ; 7=C K$-without inoculation, $8=$ Treated-without inoculation)

\section{Conclusion}

Based on the finding of the present study, it is concluded that Snef1216 (P. chrysogenum) showed plant growth-promoting characters as well as have nematicidal activities with potential biocontrol agents against RKNs on cucumber under greenhouse conditions. It can be considered as a commercial biocontrol agent, however, before recommending this Snef 1216 as commercial nematicides further study is needed to evaluate its active component screening and mechanisms of action. However, present findings may provide a theoretical foundation as a biocontrol agent for better control of root-knot nematodes (M. incognita).

Acknowledgements. The financial support provided by National Natural Science Foundation of China (31471748).

Conflict of interests. The authors have no conflict of interests.

\section{REFERENCES}

[1] Ahmad, S., Ali, H., Ur Rehman, A., Khan, R. J. Z., Ahmad, W., Fatima, Z., Abbas, G., Irfan, M., Ali, H., Khan, M. A. (2015): Measuring leaf area of winter cereals by different techniques: A comparison. - Life 13: 117-125.

[2] Aldesuquy, H., Baka, Z., Mickky, B. (2014): Kinetin and spermine mediated induction of salt tolerance in wheat plants: Leaf area, photosynthesis and chloroplast ultrastructure of flag leaf at ear emergence. - Egyptian Journal of Basic and Applied Sciences 1: 77-87.

[3] Asaduzzaman, M., Alam, M., Islam, M. (2010): Effect of Trichoderma on seed germination and seedling parameters of chili. - Journal of Science Foundation 8: 141150.

[4] Back, M., Haydock, P., Jenkinson, P. (2002): Disease complexes involving plant parasitic nematodes and soilborne pathogens. - Plant Pathology 51: 683-697. 
[5] Baermann, G. (1917): Eine einfache methode zur auffindung von Ancylostomum (Nematoden) larven in erdproben. - Geneeskd Tijdschr Ned Indie 57: 131-137.

[6] Banuelos, J., Alarcón, A., Larsen, J., Cruz-Sánchez, S., Trejo, D. (2014): Interactions between arbuscular mycorrhizal fungi and Meloidogyne incognita in the ornamental plant Impatiens balsamina. - Journal of Soil Science and Plant Nutrition 14: 63-74.

[7] Bartlett, M. S. (1937): Some examples of statistical methods of research in agriculture and applied biology. - Supplement to the Journal of the Royal Statistical Society 4: 137183.

[8] Bharath, B., Lokesh, S., Prakash, H., Shetty, H. (2006): Evaluation of different plant protectants against seed mycoflora of watermelon [Citrullus lanatus (Thunb.) Matsum and Nakai]. - Research Journal of Botany 1: 1-5.

[9] Björsell, P., Edin, E., Viketoft, M. (2017): Interactions between some plant-parasitic nematodes and Rhizoctonia solani in potato fields. - Applied Soil Ecology 113: 151-154.

[10] Divon, H. H., Fluhr, R. (2007): Nutrition acquisition strategies during fungal infection of plants. - FEMS Microbiology Letters 266: 65-74.

[11] Dong, L. Q., Zhang, K. Q. (2006): Microbial control of plant-parasitic nematodes: a fiveparty interaction. - Plant and Soil 288: 31-45.

[12] Dong, S., Qiao, K., Zhu, Y., Wang, H., Xia, X., Wang, K. (2014): Managing Meloidogyne incognita and Bemisia tabaci with thiacloprid in cucumber crops in China. - Crop Protection 58: 1-5.

[13] Dubey, S. C., Suresh, M., Singh, B. (2007): Evaluation of Trichoderma species against Fusarium oxysporum f. sp. ciceris for integrated management of chickpea wilt. Biological Control 40: 118-127.

[14] Duggal, P., Ram, S., Bhatia, A., Patil, J. (2017): Life Cycle and Pathogenicity of Meloidogyne incognita on Capsicum frutescens under Poly-House as Compared to Screen-House Conditions. - International Journal of Pure and Applied Bioscience 5: 1017-1024.

[15] Escobar, C., Barcala, M., Cabrera, J., Fenoll, C. (2015): Overview of root-knot nematodes and giant cells. - Advances in Botanical Research, Elsevier.

[16] FAOSTAT (2018): Countries - Select All; Regions - World + (Total); Elements Production Quantity; Items - Cucumbers and gherkins; Years -2016. - Retrieved 201808-25.

[17] Gotlieb, D., Oka, Y., Ben-Daniel, B.-H., Cohen, Y. (2003): Dry mycelium of Penicillium chrysogenum protects cucumber and tomato plants against the root-knot nematode Meloidogyne javanica. - Phytoparasitica 31: 217-225.

[18] Govinden-Soulange, J., Levantard, M. (2008): Comparative studies of seed priming and pelleting on percentage and meantime to germination of seeds of tomato (Lycopersicon esculentum Mill.). - African Journal of Agricultural Research 3: 725-731.

[19] Huang, W.-K., Sun, J.-H., Cui, J.-K., Wang, G.-F., Kong, L.-A., Peng, H., Chen, S.-L., Peng, D.-L. (2014): Efficacy evaluation of fungus Syncephalastrum racemosum and nematicide avermectin against the root-knot nematode Meloidogyne incognita on cucumber. - PLoS One 9: e89717.

[20] Huang, W.-K., Cui, J.-K., Liu, S.-M., Kong, L.-A., Wu, Q.-S., Peng, H., He, W.-T., Sun, J.-H., Peng, D.-L. (2016): Testing various biocontrol agents against the root-knot nematode (Meloidogyne incognita) in cucumber plants identifies a combination of Syncephalastrum racemosum and Paecilomyces lilacinus as being most effective. Biological Control 92: 31-37.

[21] Hussey, R. (1985): Staining nematodes in plant tissue - Plant nematology laboratory manual. - Amherst, MA, USA, University of Massachusetts Agricultural Experimental Station 197-199.

[22] Jang, J. Y., Choi, Y. H., Shin, T. S., Kim, T. H., Shin, K.-S., Park, H. W., Kim, Y. H., Kim, H., Choi, G. J., Jang, K. S. (2016): Biological control of Meloidogyne incognita by Aspergillus niger $\mathrm{F} 22$ producing oxalic acid. - PloS One 11: e0156230. 
[23] Jiang, M., Duan, Y., Chen, L., Zhu, X. (2011): Study on the Fermentation of Penicillium Snef1216 Inducing the Resistance of Tomato to Root-knot Nematode. - Journal of Henan Agricultural Sciences 4: 032.

[24] Kalele, D. N., Affokpon, A., Coosemans, J. (2007): Efficacy of Paecilomyces lilacinus strain 251 against root knot nematodes in tomato under greenhouse conditions. Communications in Agricultural and Applied Biological Sciences 72: 209-213.

[25] Kokalis-Burelle, N. (2015): Pasteuria penetrans for control of Meloidogyne incognita on tomato and cucumber, and M. arenaria on snapdragon. - Journal of Nematology 47: 207.

[26] Li, X., Chen, S. (2017): Screening and identification of cucumber germplasm and rootstock resistance against the root-knot nematode (Meloidogyne incognita). - Genetics and Molecular Research 16.

[27] Mao, L.-g., Wang, Q.-x., Yan, D.-d., Liu, P.-f., Jin, S., Fang, W.-s., Hu, X.-m., Yuan, L., Ouyang, C.-b., Guo, M.-x. (2016): Application of the combination of 1,3-dichloropropene and dimethyl disulfide by soil injection or chemigation: effects against soilborne pests in cucumber in China. - Journal of Integrative Agriculture 15: 145-152.

[28] Mascarin, G. M., Junior, M. F. B. (2012): Trichoderma harzianum reduces population of Meloidogyne incognita in cucumber plants under greenhouse conditions. - Journal of Entomology and Nematology 4: 54-57.

[29] Miyashita, N., Yabu, T., Kurihara, T., Koga, H. (2014): The feeding behavior of adult root-knot nematodes (Meloidogyne incognita) in rose balsam and tomato. - Journal of Nematology 46: 296-301.

[30] Mukhtar, I. (2008): Influence of Trichoderma species on seed germination in okra. Mycopath 6: 47-50.

[31] Mukhtar, I., Hannan, A., Atiq, M., Nawaz, A. (2012): Impact of Trichoderma species on seed germination in soybean. - Pakistan Journal of Phytopathology 24: 159-162.

[32] Nicol, J. M., Turner, S. J., Coyne, D. L., Nijs, L. D., Hockland, S., Maafi, Z. T. (2011): Current Nematode Threats to World Agriculture. - In: Jones, J., Gheysen, G., Fenoll, C. (eds.) Genomics and Molecular Genetics of Plant-Nematode Interactions. Springer Netherlands, Dordrecht.

[33] Oka, Y., Nacar, S., Putievsky, E., Ravid, U., Yaniv, Z., Spiegel, Y. (2000): Nematicidal activity of essential oils and their components against the root-knot nematode. Phytopathology 90: 710-715.

[34] Onkendi, E. M., Kariuki, G. M., Marais, M., Moleleki, L. N. (2014): The threat of root-knot nematodes (Meloidogyne spp.) in Africa: a review. - Plant Pathology 63: 727737.

[35] Oyarbide, F., Osterrieth, M. L., Cabello, M. (2001): Trichoderma koningii as a biomineralizing fungous agent of calcium oxalate crystals in typical Argiudolls of the Los Padres Lake natural reserve (Buenos Aires, Argentina). - Microbiological Research 156: 113-119.

[36] Palomares-Rius, J. E., Escobar, C., Cabrera, J., Vovlas, A., Castillo, P. (2017): Anatomical Alterations in Plant Tissues Induced by Plant-Parasitic Nematodes. Frontiers in Plant Science 8: 1987.

[37] Sebastian, P., Schaefer, H., Telford, I. R., Renner, S. S. (2010): Cucumber (Cucumis sativus) and melon (C. melo) have numerous wild relatives in Asia and Australia, and the sister species of melon is from Australia. - Proceedings of the National Academy of Sciences 107: 14269-14273.

[38] Selim, M. E. M. (2010): Biological, chemical and molecular studies on the systemic induced resistance in tomato against Meloidogyne incognita caused by the endophytic Fusarium oxysporum, Fo162. - PH.D. University of Bonn.

[39] Sharon, E., Chet, I., Spiegel, Y. (2009): Improved attachment and parasitism of Trichoderma on Meloidogyne javanica in vitro. - European Journal of Plant Pathology 123: 291-299. 
[40] Siddiqui, Z. A., Akhtar, M. S. (2009): Effects of antagonistic fungi, plant growthpromoting rhizobacteria, and arbuscular mycorrhizal fungi alone and in combination on the reproduction of Meloidogyne incognita and growth of tomato. - Journal of General Plant Pathology 75: 144.

[41] Smant, G., Helder, J., Goverse, A. (2018): Parallel adaptations and common host cell responses enabling feeding of obligate and facultative plant parasitic nematodes. - The Plant Journal 93: 686-702.

[42] Son, S., Khan, Z., Kim, S., Kim, Y. (2009): Plant growth-promoting rhizobacteria, Paenibacillus polymyxa and Paenibacillus lentimorbus suppress disease complex caused by root-knot nematode and fusarium wilt fungus. - Journal of Applied Microbiology 107: 524-532.

[43] Terra, W. C., Campos, V. P., Martins, S. J., Costa, L. S. A. S., da Silva, J. C. P., Barros, A. F., Lopez, L. E., Santos, T. C. N., Smant, G., Oliveira, D. F. (2018): Volatile organic molecules from Fusarium oxysporum strain 21 with nematicidal activity against Meloidogyne incognita. - Crop Protection 106: 125-131.

[44] Tian, Y., Zhang, X., Liu, J., Gao, L. (2011): Effects of summer cover crop and residue management on cucumber growth in intensive Chinese production systems: soil nutrients, microbial properties and nematodes. - Plant and Soil 339: 299-315.

[45] Trudgill, D. L., Blok, V. C. (2001): Apomictic, polyphagous root-knot nematodes: exceptionally successful and damaging biotrophic root pathogens. - Annual Review of Phytopathology 39: 53-77.

[46] Vos, C. M., Tesfahun, A. N., Panis, B., De Waele, D., Elsen, A. (2012): Arbuscular mycorrhizal fungi induce systemic resistance in tomato against the sedentary nematode Meloidogyne incognita and the migratory nematode Pratylenchus penetrans. - Applied Soil Ecology 61: 1-6.

[47] Xiang, N., Lawrence, K. S., Kloepper, J. W., Donald, P. A., McInroy, J. A., Lawrence, G. W. (2017): Biological control of Meloidogyne incognita by spore-forming plant growthpromoting rhizobacteria on cotton. - Plant Disease 101: 774-784.

[48] Yan, X.-n., Sikora, R. A., Zheng, J.-w. (2011): Potential use of cucumber (Cucumis sativus L.) endophytic fungi as seed treatment agents against root-knot nematode Meloidogyne incognita. - Journal of Zhejiang University Science B 12: 219-225.

[49] Yao, Q., Lu, X., Zhu, X., Wang, Y., Chen, L., Duan, Y. (2014): Resistance against Meloidogyne incognita in tomato induced by fermentation liquid of Penicillium chrysogenum strain 1216. - Acta Phytopathologica Sinica 44: 693-699.

[50] Youssef, R. M., Kim, K.-H., Haroon, S. A., Matthews, B. F. (2013): Post-transcriptional gene silencing of the gene encoding aldolase from soybean cyst nematode by transformed soybean roots. - Experimental Parasitology 134: 266-274.

[51] Zeng, J., Zhang, Z., Li, M., Wu, X., Zeng, Y., Li, Y. (2018): Distribution and Molecular Identification of Meloidogyne spp. Parasitising Flue-cured Tobacco in Yunnan, China. Plant Protection Science 1-7.

[52] Zheng, Z., Shetty, K. (2000): Enhancement of pea (Pisum sativum) seedling vigour and associated phenolic content by extracts of apple pomace fermented with Trichoderma spp. - Process Biochemistry 36: 79-84. 